\title{
ACCOMMODATION IN SPINAL MOTONEURONS OF THE CAT
}

\author{
Kazuo SASAKI AND Takuzo OtANI* \\ Department of Physiology, Faculty of Medicine, Kyoto University, Kyoto
}

Recently several papers appeared in succession concerning accommodation of the spinal motoneurons. Working with exponentially increasing currents applied to the toad's spinal motoneurons, ARAKI and OTANi (1959) found that the motoneuron fired from higher depolarization levels when the rate of rise of the stimulating current was reduced. Besides, they found that accommodation was considerably slower in soma-dendritic membrane than in the initial segment of axon. ARAKI (1960) studied further the effect of electrotonus on the accommodative property of the toad's spinal motoneurons.

FRANK and FUORTES (1960) have reported on the other hand that accommodation of spinal motoneurons of cats is slow and the threshold current intensity remains constant even when the slope of the current rise is varied within a considerably wide range. Similar results have been obtained also by KoIzUMI, USHIYAMA and BRoOKs (1960).

The results of the present study which will be described below are partly in agreement, and partly not, with those of just cited studies on cat montoneurons. Essential similarity was found between the present results and those previously reported on toad's motoneurons, but it was noticed that the interpretation given in the previous paper (ARAKI and OTANI, 1959) needs slight modification.

\section{METHODS}

All experiments were performed on the spinal motoneurons in the L7 segment of cats. The animal was laminectomized under Nembutal anesthesia $(25 \mathrm{mg} / \mathrm{Kg}$, intraperitoneal injection). The ventral roots were bilaterally cut from L5 to S1 segment. In some cases, the spinal cord was left attached to the intact brain, while in others it was transected at a lower thoracic level. Sometimes the dorsal roots in all lumbar and sacral segments were bilaterally cut in order to reduce the amount of synaptic inflow to the motoneuron under study. The exposed part of the spinal cord was protected with warmed liquid paraffine.

The exploration of the motoneurons was begun several hours after the laminectomy, with or without additional administrations of Nembutal. The depth of narcosis, as well as the amount of background synaptic inflow, seemed to affect the result as will be stated below. No curariform drugs were used.

Received for publication February 16, 1961

*佐々木和夫, 大谷卓造 


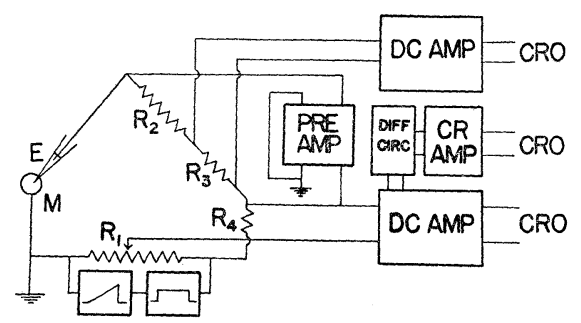

FIG. 1. Schematic illustration of the circuit for stimulation andrecording.

$\mathrm{M}$ : Motoneuron. $\mathrm{E}$ : Micropipette. $\mathrm{R}_{1}: 3 \mathrm{~K} \Omega$.

$\mathrm{R}_{2}: 100 \mathrm{M} \Omega . \quad \mathrm{R}_{3}: 1 \mathrm{M} \Omega . \quad \mathrm{R}_{4}: 10 \mathrm{~K} \Omega$.

The circuit for stimulation and recording is shown schematically in Frg. 1. Single micropipettes filled with potassium citrate were used for stimulation and simultaneous intracellular recording with the aid of a bridge circuit. Linearly increasing currents with varying inclination were delivered to the bridge as stimulation. Upon penetration of a motoneuron, the discharge of the resting membrane potential through the bridge circuit was prevented by an automatic control device similar to that reported by ITo (1958). The time course of the stimulating currents was recorded as a potential drop across a resistor of $1 \mathrm{M} \Omega\left(\mathrm{R}_{3}\right)$ inserted in the bridge. Changes in the membrane potential including action potentials were fed through a D.C. amplifier to a dual-beam oscilloscope, together with the current lead. A circuit for electrical differentiation was also attached, feeding on occasion one channel of the oscilloscope instead of the current lead.

\section{RESULTS}

I. Thresholds of motoneuron for linearly increasing currents as compared with rheobase. When a motoneuron was impaled by a micropipette and was found to be silent, rheobase was first determined by applying outward currents lasting $200 \mathrm{msec}$. or more. Then currents increasing linearly with varying gradients were applied in the order of ever decreasing gradient. Again measurements were repeated in reverse order and good agreements with previous values were ascertained. An example is given in Fig. 2. In the figure, downward displacement of the upper current beam represents the intensity of current flowing outwardly through the motoneuron membrane. The corresponding membrane potential is shown by the lower beam, depolarization upwards in the conventional way. Since the currents applied to the motoneuron were long lasting and sometimes attained considerable intensities, the voltage records were not always reliable as a measure of the threshold depolarization. Therefore, the threshold current was measured on the current beam at the moment of spike generation which was easily determined on the voltage beam. 

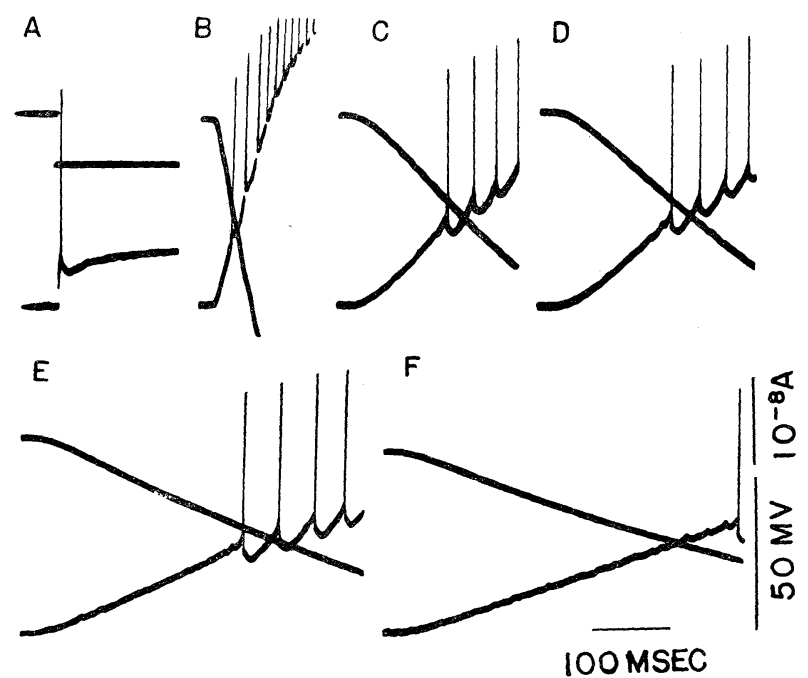

FIG. 2. Responses of a motoneuron belonging to the first group. Upper beam: Stimulating current (outward current through the motoneuron membrane gives downward displacement).

Lower beam: Voltage.

A : Rheobasic stimulation. B F : Stimulations with linearly increasing currents. The threshold current increases as the slope diminishes.

Thirty-seven motoneurons successfully studied can be classified into two groups more or less distinctively. About one third of them belonged to the first group, which gave threshold values for slowly rising currents higher than rheobase (Figs. 2, 3). The second group was characterized by its threshold current almost constant irrespective of varying slopes of the current increase (FIGs. 4, 5).

Fig. 3 shows threshold-latency curves obtained from five motoneurons which belonged to the first group. As shown in the figure, the threshold intensity of the current rising most slowly was about twice as high as the rheobase. The curve is convex upward and a marked increase in threshold intensity takes place within the latency range less than $100 \mathrm{msec}$. When the latency was prolonged over $200 \mathrm{msec}$. with ever decreasing gradient of current rise, the threshold remained almost constant, which failed the minimal gradient of effective current rise to be determined within the tested range of latency. In a few cases, the threshold showed again a slight rise, when the latent time became longer than $400 \mathrm{msec}$. The rheobase ranged between 5.3 and $7.7 \times 10^{-9} \mathrm{~A}$, which corresponded to the threshold depolarization of less than $15 \mathrm{mV}$ measured on the voltage beam.

An example of responses of a motoneuron belonging to the second group is shown in FIG. 4. The rectangular current shown in record A was of intensity a little higher than the rheobase and the motoneuron responded with repetitive firing. Even with a very slow rise of current, the threshold was remarkably low 


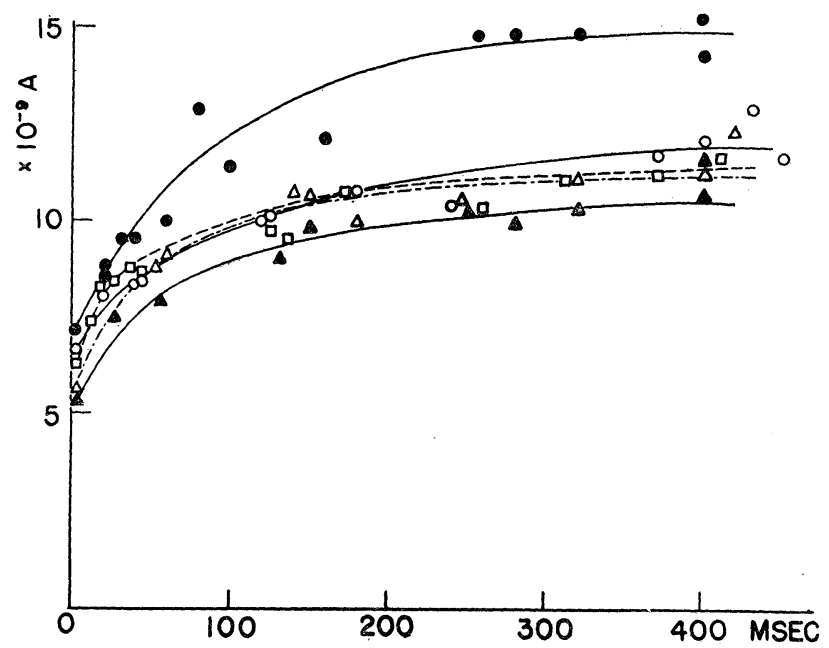

FIG. 3. Threshold-latency curves of the first group motoneurons.

Ordinates: Rheobases and the intensities of currents increasing linearly with varying slopes at the moments of spike generation.

Abscissae: Latent times.

Plots of the same sign from the same single motoneuron.
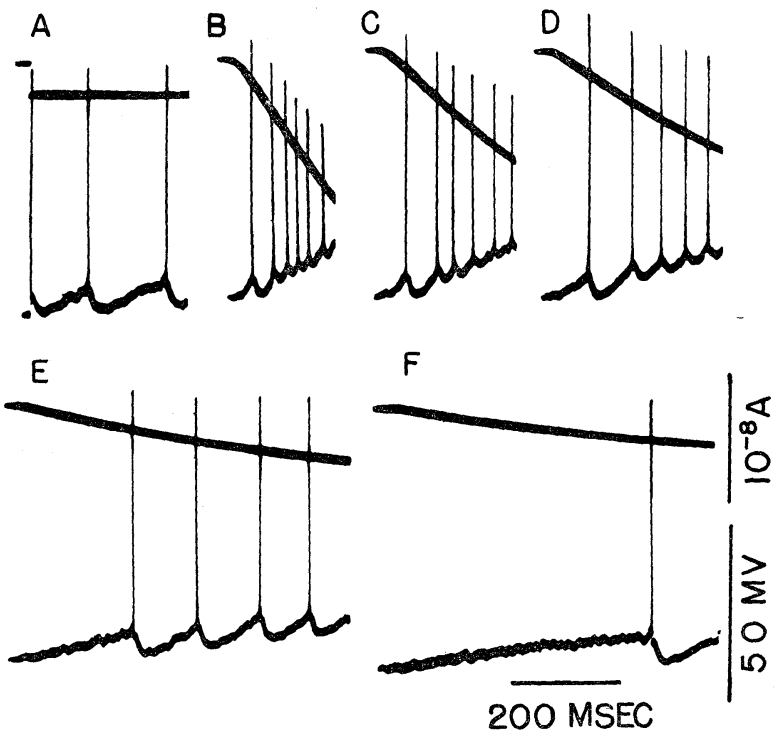

FIG. 4. Responses of a motoneuron belonging to the second group. Upper beam: Stimulating current (as in FIG. 2).

Lower beam: Voltage.

A : Slightly stronger than rheobasic stimulation.

$\mathrm{B} \sim \mathrm{F}$ : Stimulations with linearly increasing currents.

The threshold current remains almost constant. Note slower sweep speed than in FIG. 2. 


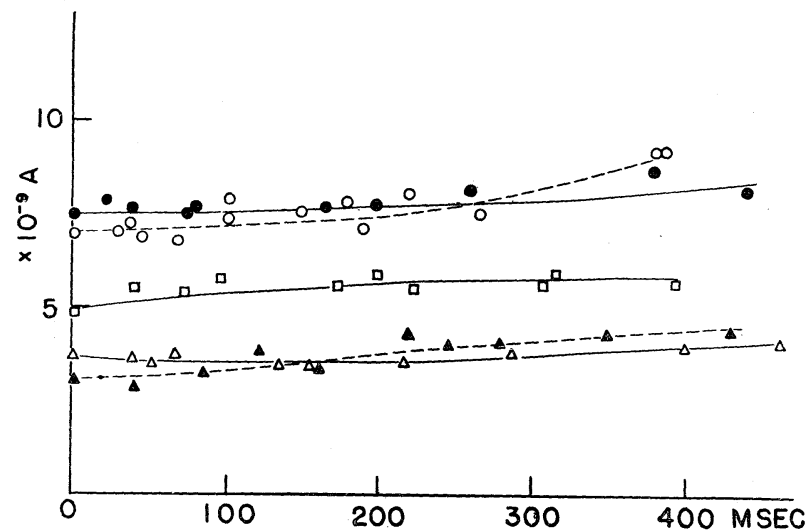

FIG. 5. Threshold-latency curves of the second group motoneurons. Description as in FIG. 3.

and constant, although it showed a tendency to increase in case the latency became longer than $400 \mathrm{msec}$. The threshold-latency curves obtained from five motoneurons of this category are presented in Fig. 5. In comparison with the first group motoneurons, these are characterized in general by a low rheobase in spite of a relatively wide diversity ranging from 3.0 to $7.5 \times 10^{-9} \mathrm{~A}$. Corresponding voltage beams measured $6 \sim 12 \mathrm{mV}$ as threshold depolarization due to rectangular currents. These values are reliable as limiting values because the responses were in these cases of short latency.

The duration of after-hyperpolarization was found on an average to be shorter in the first group motoneurons than in the second (TABLE 1).

TABLE 1

Duration of after-hyperpolarization of the first and second group motoneurons. (Summit-time in parentheses)

\begin{tabular}{|c|c|c|c|}
\hline \multicolumn{2}{|c|}{ 1st group motoneurons } & \multicolumn{2}{|c|}{ 2nd group motoneurons } \\
\hline $60^{\text {msec. }}$ & $(7-8)^{\text {msec. }}$ & 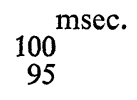 & $\begin{array}{l}\text { msec. } \\
(15)^{-} \\
(15)\end{array}$ \\
\hline 75 & $(10)$ & $\begin{array}{r}70 \\
100\end{array}$ & $\begin{array}{l}(10) \\
(15)\end{array}$ \\
\hline 80 & $(12-13)$ & $\begin{array}{l}130 \\
110\end{array}$ & $\begin{array}{r}(20-25) \\
(15)\end{array}$ \\
\hline 75 & $(12-13)$ & $\begin{array}{r}120 \\
95\end{array}$ & $\begin{array}{l}(15) \\
(15)\end{array}$ \\
\hline 70 & $(10)$ & $\begin{array}{l}100 \\
100\end{array}$ & $(15-20)$ \\
\hline Mean 72 & (11) & 102 & $(16)$ \\
\hline
\end{tabular}


II. Response of intramedullary motor axon. Sometimes the micropipette impaled a motor axon in the spinal cord which was identified by its response at a short delay to ventral root stimulation and also by the contour of the action potential.
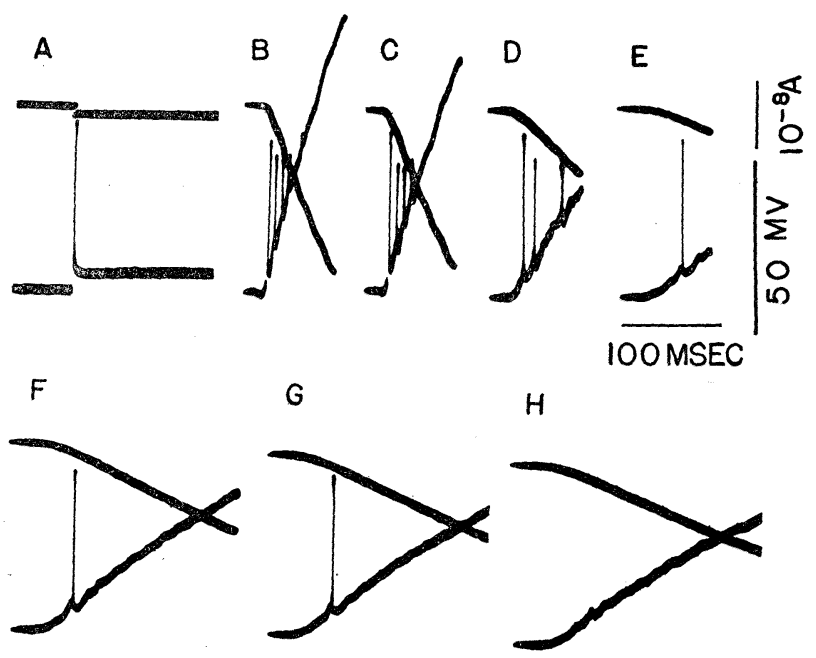

FIG. 6. Responses of an intramedullary motor axon.

Upper beam: Stimulating current (depolarizing current downward). Lower beam: Voltage. In $\mathrm{H}$, stimulation was ineffective.

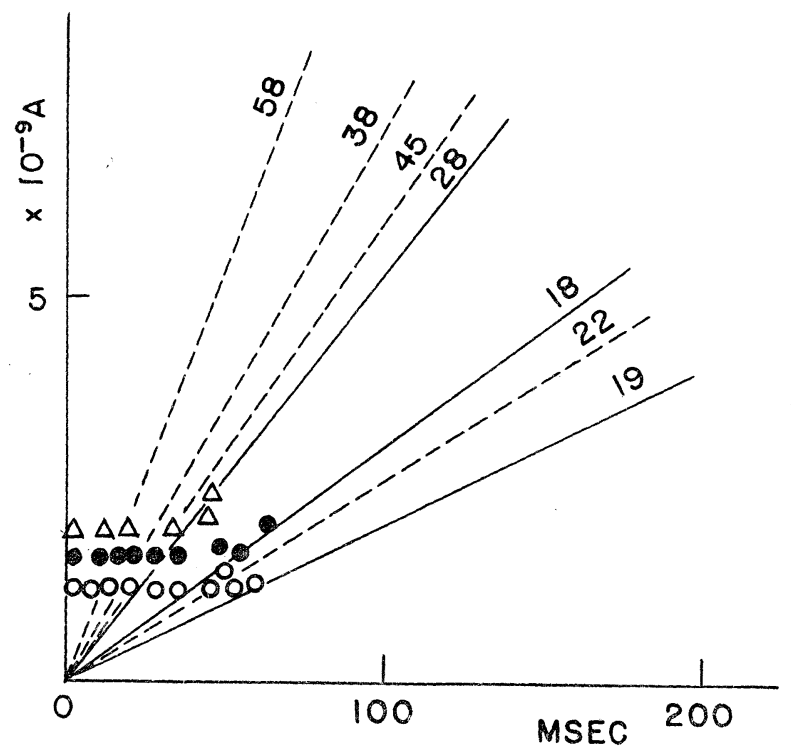

FIG. 7. Threshold-latency curves of intramedullary motor axons. Three sets of plots and their critical slopes (solid lines) and four other examples of critical slopes (dashed lines). Numerals on the slopes denote "minimal gradient" in $\mathrm{sec}^{-1}$. 
Oscilloscopic records obtained by applying currents with varying inclinations to the same axon are presented in FIG. 6, which indicates a low rheobase and relatively fast accommodation in clear contrast to Figs. 2 and 4 . In Fig. 7 are given the threshold intensities measured on three motor axons as a function of the latent time. The threshold was constant and equal to the rheobase until the gradient of current rise was reduced close to the critical value. The threshold tended to rise a little near the critical gradient below which stimulation became ineffective. Fig. 7 shows the critical gradients measured on seven axons. The 'minimal gradient' of LUCAS was found to range from 18.4 to $57.7 \mathrm{sec}^{-1}$.

III. Site of origin of spike potentials. With suspicion that the site of origin of the spike potentials may have been different depending on the gradient of stimulating currents, the spike potentials were recorded with a $\mathrm{CR}$ amplifier provided with a circuit of electrical differentiation. The results revealed that in the motoneurons showing the threshold-latency curve convex upward, the spikes were generated from different sites as the rate of current rise was varied. As shown in FIG. $8 \mathrm{~A}$, the electrically differentiated record of the intrasomatic spike evoked by a rectangular current exhibited a small but distinct step preceding the main upward deflection. As the rise of stimulating currents became slower, the step became smaller in size and duration, until it finally disappeared when the stimulating current was slow enough and the latency was longer than $50 \mathrm{msec}$. (FIG.

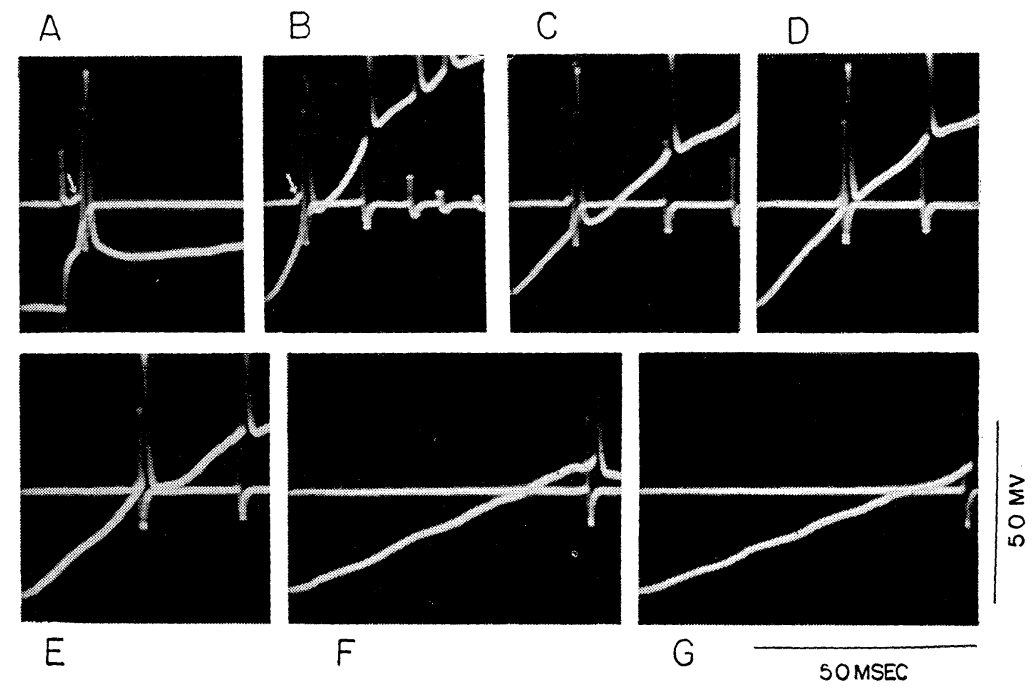

FIG. 8. Differentiated records (upper beams at start) of spike potentials of the first group motoneuron.

A : Rectangular current stimulation. Arrow (A and B) indicates the IS-step at the foot of rising phase of differentiated first spikes, which becomes progressively smaller as the slope of stimulating current decreases $(B \sim F)$ and finally disappears in G. Second and succeeding spikes are deprived of such steps. 

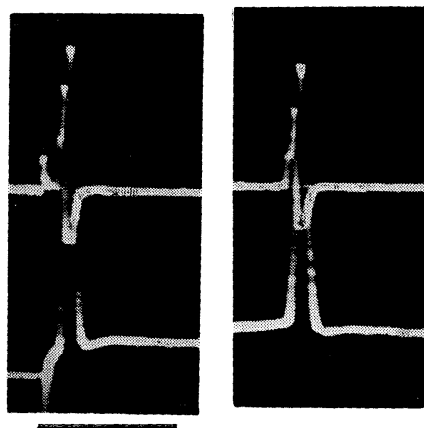

10 MSEC

FIG. 9. Differentiated records (upper beam) of spike potentials of the second group motoneuron.

Left: Rectangular current stimulation.

Right: Response of the same motoneuron stimulated with a linearly increasing current. The spike potential was elicited at a latency of 350 msec. after the onset of the current.

$8 \mathrm{G})$. Such a long latency as this corresponds already to a considerable rise of the threshold current. The results seem to indicate that the spikes are generated from the initial segment when a rectangular current is applied and from the soma when the current rise is slow enough. Consequently, increased threshold currents in the latter case seem to be attributable to the primary excitation of the soma membrane, which is known to have a threshold higher than that of the initial segment (Fuortes, Frank and Becker, 1957; Coombs, Curtis and Eccles, 1957). As to the gradual increase in the threshold current with decreasing gradient of stimulating currents, two alternative explanations are possible, which will be discussed below (see Discussion).

The same test was carried out with motoneurons whose threshold currents were almost constant in all gradient range. Differentiated records of spike potentials showed no significant difference between those evoked by a rectangular current and those by slowly rising currents, both exhibiting a more or less distinct step in the rising phase of the spike potential (FIG. 9). Thus the result indicated that in this case the initial segment had a very slow accommodation and the spikes were initiated from there even when the rise of stimulating currents was very slow.

IV. Factors affecting rate of accommodation of the initial segment. As has been mentioned in the preceding section, the rate of accommodation of IS is considerably different in individual motoneurons. This fact suggests that it may be varied also in the same motoneuron according to different environmental conditions. Though detailed relations remain to be studied, the following two points have been noted during the present study. First, deep anesthesia with Nembutal increased the chance to obtain the result of the first group. Secondly, bilateral sectioning of the dorsal roots of the lumbar and sacral segments with or without 
TABLE 2

Numbers of motoneurons of the first and second groups identified under various combinations of treatments

\begin{tabular}{l|rrrrrr}
\multicolumn{1}{c|}{ Treatment } & I & II & III & IV & V & VI \\
\hline Additional anesthetization & + & + & + & - & - & - \\
De-afferentation & + & + & - & + & + & - \\
Low spinalization & + & - & - & + & - & - \\
Number of 1st group motoneurons & 3 & 4 & 2 & 1 & 1 & 1 \\
Number of 2nd group motoneurons & 2 & 2 & 3 & 4 & 5 & 9 \\
\hline
\end{tabular}

spinal transection seemed to have the same effect as deep anesthesia (TABLE 2). All these procedures are known in common to reduce the number of impulses impinging upon the motoneurons, which may presumably play an important role in the present case. At any rate, accommodation of the initial segment seems to be most susceptible to environmental alterations.

$V$. Varying threshold depolarization in the case of synaptic excitation. While studying the effects of stimulating brain centers on the activity of lumbar motoneurons, one of the present authors (K.S.) noticed that the same motoneuron could initiate a spike potential from different levels of depolarization according to a slight difference in the rate of augmentation of the excitatory postsynaptic potentials. A short note of the results may shed a side-light on the present study, though detailed description will appear in a separate paper. FIG. 10 shows intracellular potentials recorded successively from the same cat motoneuron activated each time by stimulating ipsilateral brachium pontis with a train of short pulses whose total duration was about $2 \mathrm{msec}$. The response was characterized in general by gradually augmenting depolarization due to summated EPSP's which attained a considerable size with one or two spike potentials superimposed on it. In FIG. 10, a spike potential was generated at $17 \mathrm{mV}$ depolarization in the left record and at $25 \mathrm{mV}$ in the right, though conditions were seemingly the same. The result demonstrates that the threshold depolarization of a motoneuron may

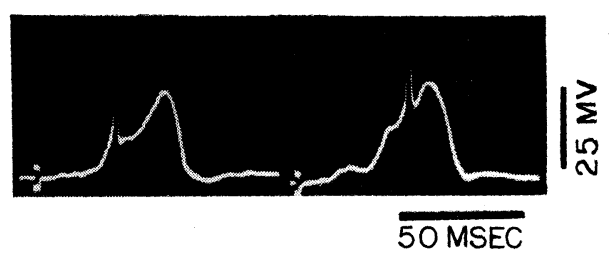

FIG. 10. Responses of a motoneuron to stimulations of ipsilateral brachium pontis.

Spikes are seen as discontinuities of the trace. Note different levels of depolarization from which the spikes start. Further description in text. 
vary according to different time course of augmenting depolarization, even in the spinal cord attached to the intact brain anesthetized very slightly with Nembutal.

\section{DISCUSSION}

As has been described, the response type of alpha motoneurons to linearly increasing currents can be classified into two. The first group shows threshold current intensities progressively higher than rheobase as the slope of current rise is reduced, whereas in the second the threshold is nearly constant over a wide range of current inclination. According to Coombs, Eccles and FatT (1955) cat motoneuron membrane shows no appreciable rectification. Therefore, the measured threshold current intensity can be regarded in linear relationship with the membrane depolarization at that moment, in so far as the time constant of the membrane is small compared with the slowness of current rise.

Although innervated muscles were not experimentally explored, the duration of after-hyperpolarization indicates that the motoneurons belonging to the first group are fast, or phasic, motoneurons and those of the second group are slow, or tonic ones (Granit, Henatsch and STeg, 1956; Eccles, Eccles and LundBERG, 1958). In fact, the first group motoneurons were found to respond repetitively to rectangular currents with much more difficulty than the second group motoneurons. They respond indeed often repetitively to linearly increasing currents, but the depolarization levels the second and succeeding spikes start from are high enough to reach the threshold of the soma membrane. Correspondingly, differentiated records demonstrate hardly any step in the rising phase of the second and succeeding spike potentials, even when the first spike shows it (FIG. 8). In the natural situations, such a high depolarization may seldom be induced by synaptic excitation and the motoneurons will exhibit phasic responses.

In the second group motoneurons, accommodation of the initial segment is also slow and, because of the low threshold of that area, they are liable to respond repetitively to relatively weak rectangular currents as well as to the train of impinging impulses in the natural situation.

An essential difference of functional significance between phasic and tonic motoneurons is therefore in the rate of accommodation of their initial segments. However, the separation of these two groups seems not to be rigidly fixed, but mutable to some extent depending on the environmental conditions, because attenuation of background synaptic inflow to the motoneuron seemed to induce higher probability of obtaining the response type of the first group. It has been already reported by Henatsch, Schulte and Busch (1959) that the actual response type of a motoneuron can be changed from phasic to tonic (or reverse) by appropriate variations of its peripheral or central excitatory inflow. They pointed out that high-frequency asynchronous and irregular background discharges from the muscle spindles were most potent to disclose latent tonic properties of 
nearly all motoneurons. These findings, together with the present results, suggest that intensive background bombardments may have some effect on the excitability in general of motoneurons in addition to their ordinary excitatory effect. It is also of interest to note that the tonic motoneurons have been known to have relatively dense synaptic contacts, both excitatory or inhibitory, on their cell bodies (ECCles, ECCles and Lundberg, 1957; Kuno, 1959).

TASAKI (1950) has reported that isolated single nerve fibers of the toad respond to linearly increasing voltage when it rises above the rheobasic voltage at a rate greater than the minimal gradient of the fiber. In the present study, the intramedullary motor axons of cats have proved to have the same property (FIG. 7). At first sight, the threshold-latency curve of the first group motoneurons, which is convex upward, would seem to be contradictory to these findings. However, this apparent discordance seems to be abolished by assuming the first explanation of the following alternatives.

The first explanation is to assume gradual transition of excitability and accommodation between the initial segment and the soma, as FUORTEs et al. (1957) did between "A" and "B" areas concerning excitability. The threshold would become gradually higher and accommodation gradually slower according to transition from the initial segment to the soma. The site of origin of the spike would then lie nearer to the soma as the current rise becomes slower, and the time interval between the onsets of both IS and SD spikes would be gradually shorter as has actually been observed as decreasing IS-steps in the differentiated records. According to this explanation, it would be possible that the threshold current at a fixed area would be constant irrespective of varying slopes of the stimulating currents, as has been known to be the case with the motor axon, except for the slowest ones near 'minimal gradient'. Presumed threshold-latency curves at the transition area and the curve experimentally observable on a motoneuron are illustrated in FIG. $11 \mathrm{~A}$.

The other alternative is to assume a sharp separation in reference to both excitability and accommodation between the initial segment and the soma, as Coombs et al. (1957) did concerning excitability of both portions. Also from this viewpoint, all of the present data seem to be accountable. Judging from the IS-steps in differentiated records, the spikes start most likely from the initial segment even when a stimulating current rises fairly slow. This means that the threshold depolarization of IS should be gradually higher as the slope of current rise is reduced. This accommodative change would account, at the same time, for the progressive attenuation of the IS-steps in the differentiated records, since the soma membrane would have been depolarized closer up to the threshold level of the soma at the time of spike initiation from IS. According to this explanation, the threshold-latency curves of IS and soma should be more or less sharply separated as illustrated in FIG. $11 \mathrm{~B}$.

In fact, the results of the present study deny neither of these alternatives 
A

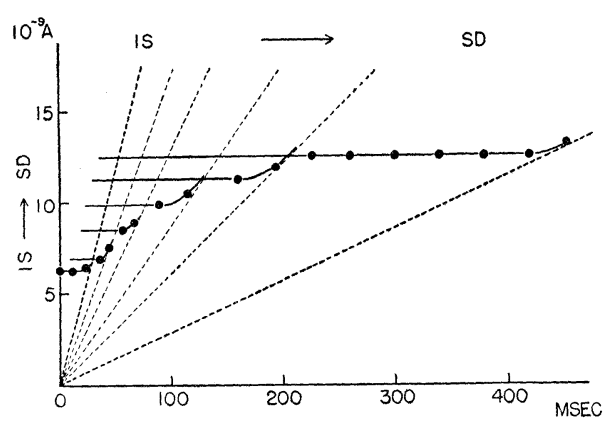

B

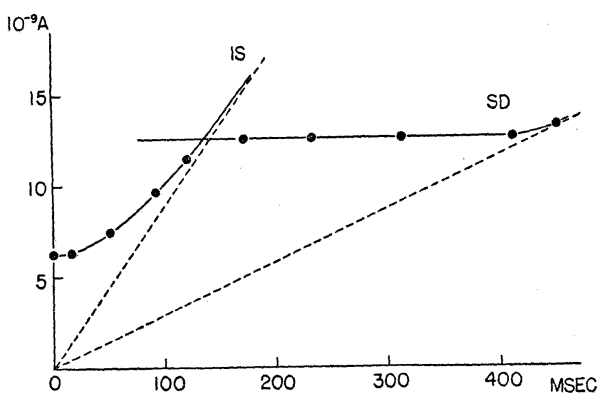

FIG. 11. Diagrams illustrating alternative hypotheses concerning accommodation of the first group motoneurons.

Ordinates: Threshold current intensity of rectangular current and the intensities of linearly increasing currents at the moments of spike generation. Abscissae: Latent times. Dots: Values experimentally observable. Dashed lines: Minimal gradients. Solid lines: Presumptive threshold depolarizations as functions of latent time.

A: Hypothesis admitting a transition zone between IS and SD where the rheobase and rate of accommodation gradually change. Threshold depolarization at each fixed area would be almost constant except for the slope of current close to the minimal gradient.

B : Hypothesis admitting no transition zone but sharp separation between IS and SD concerning excitability and accommodation. Threshold depolarization at IS should be highly dependent on the latent time.

decisively. However, the first one seems to be preferable, since it permits consistent assumption that, at a fixed area of the motoneuron, the threshold depolarization is constant within a wide range of the latent time. The assumption appears reasonable, because such relations have really been observed on the medullated axons as well as on the squid giant axon (HagiwarA et al.). Working with the toad motoneurons, AraKi and OTANi (1959) found that the threshold depolarization became greater with increasing time constants of exponentially rising stimulating currents. Unfortunately their measurements were limited to a rather narrow range of latencies, but the same discussion seems to hold also for the spinal motoneurons of the toad.

FRANK and FUORTES (1960) found that threshold current intensity of the cat motoneuron remained constant when the slope of the current rise was varied. Viewed from the present results, their measurements seem to correspond to the motoneurons of the second group. Furthermore, they found no important difference in the results obtained from different preparations, most of which were anesthetized, and a few were decerebrate or spinal. The reason of these discordances between their results and ours is not clear.

KoIzUmi et al. (1960) found in some motoneurons of the cat that, when the rate of rise of the applied current was increased gradually, only small spikes appeared as the current first became effective and further increase in rate of rise 
elicited a large full-size spike. From this, they concluded that the part of the cell from which the small spike originated was not only more sensitive but also accommodated more slowly to applied currents. This conclusion, however, seems to be less convincing, in view of the facts that the rheobase of the soma is considerably high and that the safety factor of conduction from the initial segment to the soma is so small that antidromic invasion is not infrequently blocked. Only a restricted area of the transitory zone might have primarily been excited by a trapezoid current with the slowest effective rise, and the elicited small spike might have remained abortive, being able to be conducted neither to the initial segment nor to the soma.

\section{SUMMARY}

1. Single spinal motoneurons of the cat were directly stimulated with linearly increasing currents flowing through an intracellular micropipette. Intensities of currents of varying slopes at the moment of spike generation were measured on the oscilloscopic records and compared with the rheobase.

2. According to different courses of the threshold-latency curves, the motoneurons can be classified into two groups. In the first group motoneurons, the threshold current intensity is progressively increased, to attain a certain final value, with decreasing rate of current rise. Electrical differentiation of the spike potentials reveals that they are initiated at the initial segment when the rise of current is rapid, and from the soma when the rise of current is slow enough. These motoneurons are characterized by relatively short after-hyperpolarization and considered to be phasic or fast mtoneurons.

3. The second group motoneurons have a threshold current intensity almost constant within a wide range of slopes of current rise. The spikes are initiated always at the initial segment. They are considered functionally to be tonic or slow motoneurons with the after-hyperpolarization of rather long duration.

4. Deeper Nembutal anesthesia and reduced synaptic inflow to the motoneuron seem to favor the chance to encounter the first group motoneurons. Accommodation of the initial segment is in general faster than that of the soma, but the former may change its rate with ease depending on the environmental conditions.

5. Two alternative interpretations of the threshold-latency curve of the first group motoneuron were proposed and their implications were discussed. The hypothesis admitting a transition zone between the initial segment and the soma seems to be preferable, being consistent with an assumption of constant threshold depolarization at fixed areas of the motoneuron. 


\section{REFERENCES}

1) ARAKI, T. Effects of electrotonus on the electrical activities of spinal motoneurons of the toad. Jap. J. Physiol. $10: 518-532,1960$.

2) ARAKI, T. AND OtANI, T. Accommodation and local response in motoneurons of toad's spinal cord. Jap. J. Physiol 9: 69-83, 1959.

3) Coombs, J. S., Curtis, D. R. ANd ECcles, J. C. The interpretation of spike potentials of motoneurones. J. Physiol. 139: 198-231, 1957.

4) Coombs, J. S., ECCles, J. C. AND FATT, P. The electrical properties of the motoneurone membrane. J. Physiol. $130: 291-325,1955$.

5) ECcles, J. C., ECCles, R. M. AND LUNDBERG, A. The convergence of monosynaptic excitatory afferents on to many different species of alpha motoneurones. J. Physiol. $137: 22-50,1957$.

6) ECcles, J. C., Eccles, R. M. ANd LundBeRg, A. The action potentials of the alpha motoneurones supplying fast and slow muscles. J. Physiol. 142 : 274-291, 1958.

7) Frank, K. AND Fuortes, M. G. F. Accommodation of spinal motoneurones of catsArch. ital. Biol. 98 : 165-170, 1960.

8) Fuortes, M. G. F., Frank, K. ANd Becker, M. C. Steps in the production of moto. neuron spikes. J. Gen. Physiol. $40: 735-752,1957$.

9) Granit, R., Henatsch, H. D. and Steg, G. Tonic and phasic ventral horn cells differentiated by post-tetanic potentiation in cat extensors. Acta Physiol. scand. 37: 114126, 1956.

10) Hagiwara, S. et al. (Unpublished). Cited from TASAKI "Conduction of the nerve impulse" in FIELD's Handb. of Physiol. Soc. 1, Vol. I, 1959.

11) Henatsch, H. D., Schulte, F. J. ANd Busch, G. Wandelbarkeit des tonisch-phasischen Reaktionstype einzelner Extensor-Motoneurone bei Variation ihrer Antriebe. Pflugers Archiv 270: 161-173, 1959.

12) Іто, M. A microelectrode investigation into a toad's spinal ganglion cell. Medical Science 9 : 12-20, 1958 (Japanese).

13) Koizumi, K., Ushiyama, J. AND Brooks, C. M. Effect of hypothermia on excitability of spinal neurons. J. Neurophysiol. 23: 421-431, 1960.

14) Kưo, M. Excitability following antidromic activation in spinal motoneurones supplying red muscles. J. Physiol. 149 : 374-393, 1959.

15) TASAKI, I. Electrical excitation of the nerve fiber. Part I. Excitation by linearly increasing currents. Jap. J. Physiol. 1: 1-6, 1950.

Note added in proof. An important paper by BRADLEY and SOMJEN (1961) arrived while this article was in the press. Their 'high-ceiling' type of accommodation seems to correspond to the response type of the first group motoneurons in this article, while their 'low-ceiling' type to that of the second group motoneurons.

BRAdLey, K. and SOMJEN, G. G. Accommodation in motoneurones of the rat and the cat. J. Physiol. 156 : 75-92, 1961. 